\section{Primary prevention of hemoglobinopathies by prenatal diagnosis and selective pregnancy termination in a Muslim country: Oman}

\author{
Suha Mustafa Hassan, ${ }^{1,2}$ Egbert Bakker, ${ }^{2}$ \\ Cornelis L. Harteveld, ${ }^{2}$ \\ Piero C. Giordano ${ }^{2}$ \\ 'Molecular Genetic Laboratory, National \\ Genetic Centre, Muscat, Oman; \\ ${ }^{2}$ The Reference Hemoglobinopathies \\ Laboratory, Department of Human and \\ Clinical Genetics, Leiden University \\ Medical Centre, Leiden, The Netherlands
}

\section{Abstract}

Hemoglobinopathies (HBP) are the most common genetic disorder in 0man and are in need of prevention programs due to the high incidence of $\beta$-thalassemia major and sickle cell disease. Prenatal diagnosis (PD) and selective pregnancy termination is shown to be the most effective prevention tool for the control of HBP. However, PD is not available in Oman thus far because abortion is subject to religious, cultural and ethical issues. We have examined the attitude of a number of Omani HBP carrier couples towards prenatal diagnosis and selective abortion. We have interviewed 35 couples at risk visiting the main premarital clinic in Muscat between Jan 2011 and Jan 2012. Couples were interviewed using a pre-structured questionnaire. The majority would have accepted prenatal diagnosis (94\%) if the service would be available in the country but pregnancy termination was greatly influenced by religious values.

\section{Introduction}

Severe hemoglobinopathies (HBP), such as $\beta$-thalassemia major (TM) and sickle cell disease, are endemic in Oman. These diseases cause a huge suffering to patients and families and create an enormous healthcare burden to the country. Around $\sim 6 \%$ of the population are carriers of sickle cell whereas about $\sim 3 \%$ are carriers of $\beta$-thalassemia. ${ }^{1,2}$ The diseases can be prevented by screening carriers before marriage, before reproduction or in early pregnancy and by offering genetic counseling. If the couples are already married, the most usual preventative option is prenatal diagnosis (PD) which is offered to couples at risk in many

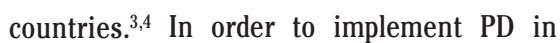
Oman, one should know if these interventions would be accepted by the population and if pregnancy termination, in case of a severely affected fetus, would be accepted since selective abortion on medical indication is restricted in Oman because of religious, legal, ethical and social implications. Omanis are Muslims with a high rate of consanguineous marriages and couples at risk for HBP are therefore quite common. If these couples are to seek for PD, they are forced to do it abroad. Different Muslim countries and institutions have different opinions towards medical abortion. Most prohibit pregnancy termination at any time unless the mother's life is at threat. Others allow it only within the first 120 days of gestation if the fetus is severely affected. ${ }^{5}$ In some Muslim Arab countries such as Tunisia ${ }^{6}$ and Egypt, ${ }^{7}$ PD and interruption of pregnancy is well accepted and currently offered to couples at risk to prevent severely affected progeny.

Premarital screening for $\beta$-thalassemia is subsidized and funded by the Omani government but it is not mandated by law as it is the case with neighboring Muslim countries such as United Arab Emirates and Iran. The national prevention program in Oman involves; carrier detections, molecular diagnostics in case of un-clear hematological findings, and genetic counseling. The prevention option thus far is not to marry if both partners are at risk. This study evaluates the implementation of HBP prevention in Oman in view of carrier couples towards PD and pregnancy termination.

\section{Materials and Methods}

Data were obtained from the primary premarital clinic in Muscat. Detection of carriers was confirmed by hematological tests. A questionnaire was designed (Table 1) and couples in which both partners were carriers were surveyed. The survey questionnaire included sex, age, degree of consanguinity, risk acceptance and opinion concerning prenatal diagnosis and medical abortion in case of an affected fetus. The concept of prenatal diagnosis was explained to all participants. The median age of participants was 25 years old and all participants were of Omani nationality and Muslim.

\section{Results}

From 420 couples visiting the main pre-marital clinic in Muscat between January 2011 to January 2012, 38 couples were found in which both partners were carriers of either $\beta$-thalassemia trait or sickle cell trait. Three carrier couples did not want to undergo the survey, so
Correspondence: Suha Mustafa Hassan, Hemoglobinopathies Laboratory, Molecular Genetics, Genetics Center, Ministry of Health, Muscat, Oman.

E-mail: suha_85@hotmail.com

Key words: prenatal diagnosis, medical abortion, Islam, Oman.

Conflicts of interest: the authors declare to have conducted this study in accordance with local ethical regulations and to have no conflicts of interest on the presented matters.

Received for publication: 22 May 2014

Accepted for publication: 31 July 2014.

This work is licensed under a Creative Commons Attribution 3.0 License (by-nc 3.0).

(C) Copyright S.M. Hassan et al., 2014

Licensee PAGEPress, Italy

Thalassemia Reports 2014; 4:4171

doi:10.4081/thal.2014.4171

35 couples were interviewed and it was found that $40 \%$ of the couples were first cousins. Twenty-five couples (71\%) underwent premarital testing and genetic counseling prior to marriage while the remaining $29 \%$ visited the premarital clinic after getting married and after getting an affected child. Out of the 25 couples who received counseling prior to marriage, 10 couples still decided to continue with the marriage while 15 broke the engagement and went to seek for a non-carrier partner. Out of the 10 couples who got married, 6 couples accepted the risk of getting an affected child while 4 couples did not and decided not to get any children. From the carrier couples who were counseled after getting an affected child, $20 \%$ travelled abroad for PD. The remaining decided not to get pregnant again. Out of the 35 couples, 33 couples would have undergone prenatal diagnosis if the service was available in the country but out of these 33 couples, 10 would not undergo selective abortion even if it was religiously allowed. Results are summarized in Table 2.

We further surveyed 20 selected couples in which only one partner was found to be a carrier; 10 male carriers engaged to normal female partners and 10 female carriers engaged to normal male partners to see if there is any bias between the different genders in marrying a carrier partner. Among the first group, 4 out of 10 were first cousins and one couple broke the engagement after finding out the female was a carrier. Among the second group, 2 out of 10 were first cousins and all couples continued with their marriages. 


\section{Discussion}

Prenatal diagnosis is a highly sensitive issue in 0man. In order to establish PD service in the country, awareness and knowledge should be clearly addressed to the targeted group and religious authority for a further discussion on the issue of medical abortion in case of a severely affected fetus. Based on our survey, the majority of the informed couples accepted to undergo PD if the service would be available in Oman but only if termination of pregnancy would be approved by the country's Mufti. The majority of the participants were unaware of the Fatwa approved in some ArabMuslim countries allowing selective abortion within the first trimester in case of an affected fetus based upon Islamic jurisprudence (Council of the World Islamic League, 1522/07/1410 Hijri/ 10-17 February 1990). However, this Fatwa is not accepted by all Muslim leaders/scholars. Participant's attitude was greatly influenced by Oman's Mufti's opinion and country's policy. Although it might seem reasonable, the relation between $\mathrm{PD}$ and abortion is not absolute. As a matter of fact, in countries offering PD, couples getting a positive PD result may still decide to keep the affected fetus. On the other hand, because of the $1-2 \%$ chance of losing a fetus due to procedure risk, PD is discouraged if the couples are not planning to interrupt pregnancy in case of a severely affected fetus. Therefore the abortion debate should not be an issue for health care leaders to discourage the implementation of a national PD service. PD can help the couple to decide whether or not to interrupt the pregnancy abroad or can prepare them if they decide to keep an affected child so they are mentally and psychologically ready on how to cope with such a situation. PD would be a useful tool for clinicians as well in order to plan a properly tailored treatment at an early stage.

Although the majority of our enquired couples were in favor of PD, accepting abortion was tightly bound to religious rules. This emphasizes the critical role of religion in decision making in the Omani population who are known for their strict Islamic practice in the Arabian Gulf. The same impact of religious convictions on accepting PD has also been previously described in Saudies. ${ }^{8}$

In a number of Muslim countries, the national premarital programs are mandatory and aimed at limiting marriage between carriers. In Iran, renouncing to marriage have been gradually replaced by PD and selective abortion and national incidence of TM has fallen from over 2000 cases a year to nearly zero affected newborn in some well managed regions of the country. ${ }^{9}$ Iran, with the majority being of Shia'a sub-religion, some of the Shia'a scholars allowed medical abortion before the $16^{\text {th }}$ week of gestation under certain circumstances. ${ }^{10}$

Although most Muslim countries are of Sunni sub-religion, some countries have accepted pregnancy termination under specific circumstances while others prohibited it absolutely. This is due to the four orthodox divisions in the Sunnis leading to diverse opinions towards medical abortion ${ }^{11}$ as well as to the legal base system in a country which might not be exclusively religion-based but could be civil-based or a combination of both. ${ }^{11}$

In Oman, medical abortion is thus far prohibited by religion and law. The majority of the people in Oman are of Abadhi sub-religion. The main Abadha scholar in Oman, who is also the country's Mufti, believe that human should not interfere with God's will and perceive that termination of a pregnancy should only take place if the pregnancy is putting the mother in a life threatening condition.

Despite well organized pre-marital clinics, the birth of HBP children is still very high in Oman. A large portion of the population may remain un-diagnosed due to social stigmatization and unawareness. The concept of recessive disease might be difficult to understand for non-medically-educated couple and the reaction why should I get an affected child if I am a totally healthy person? might explain why people continue with their marriage plans regardless the $25 \%$ risk of getting a severely affected child.

Since PD is not offered to couples at risk in Oman thus far, the other primary prevention option besides not marrying, is selecting healthy gametes for fertilization by preimplantation genetic diagnosis (PGD) which is also not available in the country. PGD is permissible in Islam provided that the gametes are from the husband and wife. ${ }^{12}$ PGD may be socially a better option and more easily acceptable than PD in Muslim countries as parents do not have to undergo the option of terminating the pregnancy. ${ }^{13}$ However, clinically it involves a considerable hormonal treatment for the woman and artificial insemination may cause an increase in chromosomal defects.

Table 1. Questionnaire used for the survey in this study.

Name:

Tribe:

Sex:

Age:

Region:

Diagnosis:

Occupational status:

Relationship to partner (e.g. ${ }^{\text {st }}$ cousins)?

Screened prior/after marriage?

Counseled prior/after marriage?

Understood all the information provided by the counselor? (yes/no)

Carried with the marriage regardless of the risk? (yes/no)

Accepted the risk of $1 / 4$ chance of getting an affected child? (yes/no)

Heard of PND before? (yes/no)

Would undergo PND if service is available in the country? (yes/no)

In case of carrying an affected fetus, would accept terminating the pregnancy? (yes/no) reasons? (e.g.religion, legality, ethics, culture, personal believes?)

PND, prenatal diagnosis.

Table 2. Summary of the Omani couples views towards prenatal diagnosis and pregnancy termination of affected fetus.

\begin{tabular}{lc} 
Omani couples & No. \\
Couples interviewed & 35 \\
Consanguineous & 14 \\
\hline Couples in which both are carriers & 35 \\
Couples counseled before marriage & 25 \\
\hline Couples counseled after marriage & 10 \\
Couples who would go for PD & 33 \\
\hline Couples who would abort if religiously allowed & 25 \\
\hline
\end{tabular}

$\mathrm{PD}$, prenatal diagnosis. 
Moreover it is a technically complex procedure and has some limitation with concerns of multiple pregnancies or un-successful implantation and of course economically this procedure is quite expensive. Only couples who are financially capable to cover the costs can travel abroad for PGD where's the majority have to cope with the risk of getting another affected child or decide not to plan another pregnancy.

In a country such as Oman, where there are high rates of both consanguinity and hemoglobinopathies, it is the task of the health care authorities to debate the issue with the Country's Islamic leader or Mufti to consider medical abortion for severe genetic conditions. Moreover, public health authorities should be concerned with the awareness of the public and should educate couples at risk on the availability of alternative preventative services. For the time being, early population screenings and genetic counseling are the only available preventative measures for the control of sickle cell disease and $\beta$-thalassemia major. With good infrastructure and implementing successful strategies, incidence of hemoglobinopathies could be dramatically reduced in Oman.

\section{References}

1. Al-Riyami AA, Suleiman AJ, Afifi M, et al. A community- based study of common hereditary blood disorders in Oman. East Mediterr Health J 2001;7:1004-11.

2. Alkindi S, Al Zadjali S, Al Madhani A, et al. Forecasting hemoglobinopathy burden through neonatal screening in Omani neonates. Hemoglobin 2010;34:135-44.

3. Hamamy HA, Al-Allawi NAS. Epidemiological profile of common haemoglobinopathies in Arab countries. J Community Genet 2013;4:147-67.

4. Hoppe CC. Prenatal and newborn screening for hemoglobinopathies. Int $\mathrm{J}$ Lab Hematol 2013;35:297-305.

5. Al Aqeel. Ethical guidelines in genetics and genomics. An Islamic perspective. Saudi Med J 2005;26:1862-70.

6. Chaabouni H, Chaabouni M, Maazoul F, et al. Prenatal diagnosis of chromosome disorders in Tunisian population. Ann Genet 2001;44:99-104.

7. El-Beshlawy A, El-Shekha A, Momtaz M, et al. Prenatal diagnosis for thalassaemia in Egypt: what changed parents' attitude? Prenat Diagn 2012;32:777-82.
8. Alkuraya FS, Kilani RA. Attitude of Saudi families affected with hemoglobinopathies towards prenatal screening and abortion and the influence of religious ruling (Fatwa). Prenat Diagn 2001;21:448-51.

9. Joulaei H, Shahbazi M, Nazemzadegan B, et al. The diminishing trend of -thalassemia in southern Iran from 1997 to 2011: the impact of preventive strategies. Hemoglobin 2014;38:19-23.

10. Abolghasemi H, Amid A, Zeinali S, et al. Thalassemia in Iran - epidemiology, prevention, and management. J Pediatr Hematol Oncol 2007;29:233-8.

11. Shapiro GK. Abortion law in Muslimmajority countries: an overview of the Islamic discourse with policy implications. Health Policy Plan 2013;29:1-12.

12. Al-Sulaiman A, Al-Odaib A, Al-Rejjal R, Hewison J. Preimplantation genetic diagnosis in Saudi Arabia: parents' experience and attitudes. Prenat Diagn 2010;30:753-7.

13. Farra C, Nassar AH, Usta IM, et al. Acceptance of preimplantation genetic diagnosis for $\beta$-thalassemia in Lebanese women with previously affected children. Prenat Diagn 2008;28:828-32. 